\title{
Numerical Model Analysis of Natural Gas Combustion Burners
}

\author{
A. IBRAHEEM ${ }^{1}$, F. SZODRAI ${ }^{2}$ \\ ${ }^{1}$ University of Debrecen, Faculty of Engineering, Department of Mechanical Engineering, \\ amjdibraheem@gmail.com \\ ${ }^{2}$ University of Debrecen, Faculty of Engineering, Department of Building Services and Building Engineering, \\ szodrai@eng.unideb.hu
}

Abstract. Traditional power plants still the dominating power source for all the major industries and power demanding facilities, the most crucial facility for the whole plant operations is the industrial boiler which generates steam, heating energy or electrical power. Boilers generate energy by combustion. The improvement of combustion efficiency could greatly influence the energy consumption and will make the boiler more efficient and cleaner (less emissions), that's why it is important to understand the combustion and thermal flow behaviours inside the boiler. Beside experimental testing, computational work nowadays becoming more and more important due to lower cost and acceptable accuracy with minimum error. With numerical calculations method, the computational model created by a Computational Fluid Dynamics (CFD) software could reduce a lot of trial and error on experimental work. In this paper utilizing the ANSYS FLUENT 19.1 software to make crate the combustion model. The ratio of air to fuel mixture, the equivalency factor, mass flow rate of the mixture, velocity, mass fractions of the mixture components (fuel and air) and their temperatures will serve as the input parameter while the exhaust gases component mass fraction, temperature, mass flow and velocity will be monitored.

Key words: combustion, boiler, burner, efficiency, performance, CFD, Fluent.

\section{Introduction}

Substitution of oil with natural gas in industrial and utility boilers is one of the ways to step up to the goal for optimizing energy consumption and environmental protection. Usage of natural gas instead of crude oil in combustors eliminates the $\mathrm{SO}_{\mathrm{x}}$ formation and, with integration of measures for reduction of $\mathrm{NO}_{\mathrm{x}}$ emission, it is very attractive, particularly for boilers located in urban areas. [1]

In the heat centre of DOTE Debreceni Orvostudományi Egyetem (University of Medical Sciences), several steam and hot water boilers operate both on natural gas and fuel oil (Mazut) they were installed in 1998 and they produce steam and district heating for this institution. [2]

Our research project is to study the boilers operation and efficiency under different circumstances by the alternation of the various combustion parameters. ANSYS Fluent 19.1 CFD software will be used as a tool to create the model of the mentioned boiler. The CFD model offers a relatively quick, reliable and cost-effective tool to create flow fields, temperature, kinetic energy, emission distribution of a boiler. It can be used to investigate boiler performances. With adequate technical parameters it also provides engineers accurate predictions of how can a boiler perform under various conditions, including 
alternate fuel firing. The computer simulation using the ANSYS Fluent 19.1 code provides information that can be difficult to measure in a physical model.

There was a lot of efforts to simulate the burner combustion reaction along the past few years.

In 2013 Noor et.al. published a paper titled "Detail guide for CFD on the simulation of biogas combustion in bluff-body mild burner" it was a good take in simulating the combustion reaction and its effect on the burner efficiency using Ansys Fluent and they stressed on the importance of a fine mesh to get a good results. It has to be mentioned that the fuel used was a single species fuel. [5]

In 2007 Indrusiak et.al. published a research titled "CFD analysis of the combustion gas flow and heat exchange processes in a boiler of a thermal power plant" and the code showed a good sensibility to variations in inlet and boundary conditions and this was explored to study the performance of the boiler at out of design and part-load operation conditions. Also, the combustion, the heat exchange processes and the $\mathrm{NO}_{\mathrm{x}}$ formation responses to other conditions at the burners. The vertical tilt was studied, but the fuel used was coal. [6]

In 2013 Devadiga et.al. published a paper titled "Optimizing Bunsen burner Performance Using CFD Analysis" and the pointed out that the overall flame structure can be controlled by changing the various reactant velocities and equivalence ratios and they stressed on the importance of the interaction between the reaction zone, but they had a problem in the difference between the computed temperatures and the experimental temperatures. [7]

\section{Materials and methods}

In our paper we examined a simplified version of the boilers that are used in the heat centre. In the Heat centre two AKH-4/12 steam boiler and two AKH 7500M hot water boiler (figure 1.) and an auxiliary steam boiler can be found. The rated capacity of the steam boilers are $2.67 \mathrm{MW}$ while the hot water boilers are $7.5 \mathrm{MW}$, heated surface is $93.6 \mathrm{~m}^{2}$ and $223.94 \mathrm{~m}^{2}$ respectively. The boilers rated efficiency are around $92 \pm 1 \%$. [3] The simulation model had similar geometry to the hot water boilers, one of our further goal is to make a more precise geometry model for the mentioned devices.

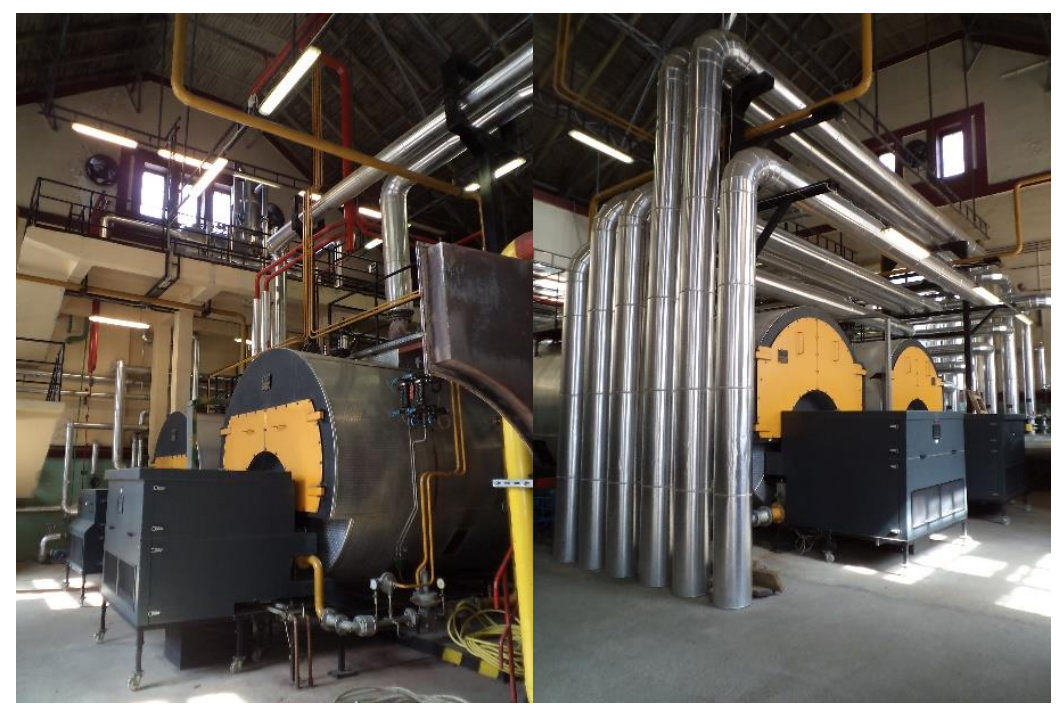

Figure 1: AKH-4/12 steam boilers (left side) and AKH 7500M hot water boilers (right side) 


\section{Combustion model}

The general combustion requires fuel, air and activation energy and it produces vapor and flue gas, which is the emission that we want to reduce

In this paper a simple natural gas fuel composition was used that contained methane as the main component besides carbon dioxide, nitrogen, ethane, propane, butane and pentane. The detailed molar distribution can be seen in table 1 .

Table 1: fuel composition in [mol \%]

\begin{tabular}{ccccc}
\hline Carbon dioxide & Nitrogen & Methane & Ethane & Propane \\
\hline $1.169_{\mathrm{mol}} \%$ & $0.907 \mathrm{~mol}_{\mathrm{mo}} \%$ & $94.339_{\mathrm{mol}} \%$ & $2.773_{\mathrm{mol}} \%$ & $0.811_{\mathrm{mol}} \%$ \\
\hline
\end{tabular}

The molar fraction can be transferred into mass fraction the number of moles (n) [kmol] equals the molecular mas $(\mathrm{m})[\mathrm{kg}]$ divided by the molar mas $(\mathrm{M})\left[\mathrm{kg} \mathrm{kmol}^{-1}\right]$ :

$\mathrm{n}=\mathrm{m} \cdot \mathrm{M}^{-1}$

Air contained of oxygen and nitrogen the molar fraction was $\left(0.21 \mathrm{~mol} \% \mathrm{O}_{2}\right.$ and 0.79 mol $\left.\% \mathrm{~N}_{2}\right)$ while the mass fraction was $\left(0.233 \mathrm{~m} \% \mathrm{O}_{2}\right.$ and $\left.0.767 \mathrm{~m} \% \mathrm{~N}_{2}\right)$.

AFR - The air-fuel ratio [-] gives a mass ratio in the fuel-air mix at any given moment that was calculated by the following:

$\mathrm{AFR}=\mathrm{m}_{\text {air }} \cdot \mathrm{m}_{\text {fuel }^{-1}}$

$\mathrm{m}_{\text {air }}$ - mass of air $[\mathrm{kg}]$

$\mathrm{m}_{\text {fuel }}$ - mass of fuel [kg]

The stoichiometric ratio $(\lambda)[-]$ is the AFR normalized with respect to stoichiometric AFR.

$\Phi$ - fuel-air equivalence ratio [-]

$\Phi=\lambda^{-1}$

If the $\Phi$ less than one the combustion is incomplete due to the fuel is too rich, this can show an increased emission level, when this value equals with 1 the combustion is ideal. When the $\Phi$ larger than one it means the fuel amount is lean. [4]

\section{Chemical equations}

1- $\mathrm{CH}_{4}$ (Methane) combustion:

$\mathrm{CH}_{4}+2 \mathrm{O}_{2}=\mathrm{CO}_{2}+2 \mathrm{H}_{2} \mathrm{O}$

2- $\mathrm{C}_{2} \mathrm{H}_{2}$ (Ethane) combustion:

$\mathrm{C}_{2} \mathrm{H}_{2}+3.5 \mathrm{O}_{2}=2 \mathrm{CO}_{2}+3 \mathrm{H}_{2} \mathrm{O}$

3- $\mathrm{C}_{3} \mathrm{H}_{8}$ (Propane) combustion:

$\mathrm{C}_{3} \mathrm{H}_{8}+5 \mathrm{O}_{2}=3 \mathrm{CO}_{2}+4 \mathrm{H}_{2} \mathrm{O}$

From the above equations we can find that burning $1 \mathrm{kmol}$ of the fuel will consume $2.024 \mathrm{kmol}$ of $\mathrm{O}_{2}$ and depending on the molar fraction of $\mathrm{O}_{2}$ in the air which is $21 \mathrm{v} \%$ we can find that burning $1 \mathrm{kmol}$ of fuel will consume $9.64 \mathrm{kmol}$ of air.

Then we can calculate the air to fuel ratio:

$\frac{A}{F}=\frac{m_{\text {air }}}{m_{\text {fuel }}}=\frac{n_{\text {air }} \cdot M_{\text {air }}}{n_{\text {fuel }} \cdot M_{\text {fuel }}}=5.687 \frac{\mathrm{kg}_{\text {air }}}{\mathrm{kg}_{\text {fuel }}}$ 


\section{Calculating the fuel mass flow}

The fuel mass flow rate is estimated based on the boiler load required with respect to the specific heat generated by one mass unit of fuel, in other words, the net heat value which is the lower heating value of that fuel.

In our case the boiler load is $35 \mathrm{~kJ} \mathrm{~s}^{-1}$ and the lower heating value is LHV= $47.310^{3} \mathrm{~kJ} \mathrm{~kg}^{-1}$, then the total fuel mass flow rate is: $7.42610^{-4} \mathrm{~kg} \mathrm{~s}^{-1}$, and since we have 6 fuel injectors then the fuel mass flow rate in each injector is $1.23710^{-4} \mathrm{~kg} \mathrm{~s}^{-1}$.

\section{Calculating the air mass flow}

Depending on the fuel mass flow and the air to fuel ratio we can calculate the total air mass flow which is $4.22410^{-3} \mathrm{~kg} \mathrm{~s}^{-1}$, this mass flow is divided between the main air inlet and the secondary air inlet as $75_{\mathrm{v}} \%$ of air coming from main air inlet and $25 \mathrm{v} \%$ of air coming from secondary air inlet.

Main air inlet mass flow rate: $2.91510^{-3} \mathrm{~kg} \mathrm{~s}^{-1}$.

Secondary air inlet mass flow rate: $2.42910^{-4} \mathrm{~kg} \mathrm{~s}^{-1}$.

\section{Results and discussion}

The research started with a standard gas can combustor with primary air inlet and fuel inlet and secondary air inlet. The mesh was built from $10^{-3} \mathrm{~m}$ large tetrahedrons, due to high velocity no inflation layer was applied. In the ANSYS Fluent 19.1 energy equation and K- 3 turbulence for the viscosity model was used.

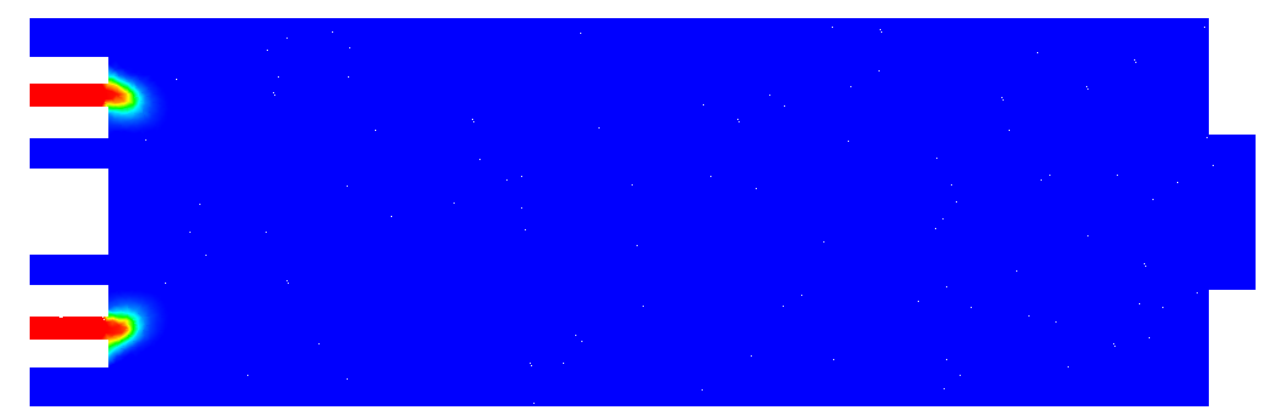

Figure 2: $\mathrm{CH}_{4}$ distribution (colour code: red $100{ } \%$, blue $0_{v} \%$ )

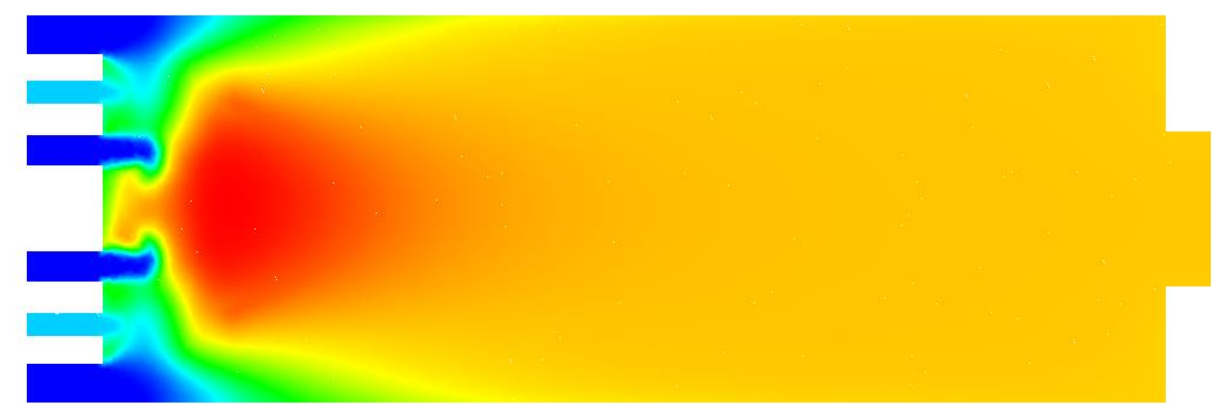

Figure 3: $\mathrm{CO}_{2}$ distribution (colour code: red $0.11_{v} \%$, blue $0_{v} \%$ ) 


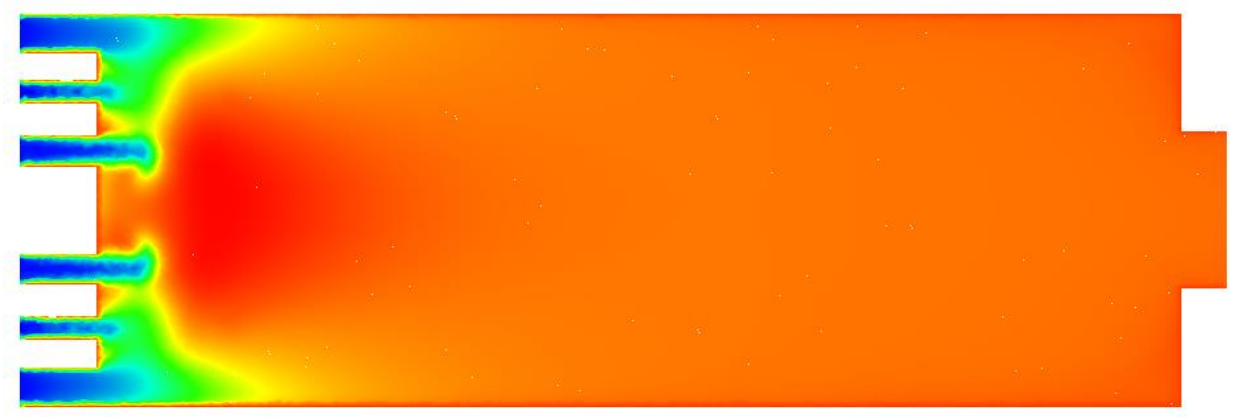

Figure 4: Temperature distribution (colour code: red $2440 \mathrm{~K}$, blue $388 \mathrm{~K}$ )

From figure 2. it can be seen that the complete combustion happened, the $\mathrm{CH}_{4}$ formation that was indicated with red colour was consumed during the combustion. While it is observable in figure 3. that the fuel was converted into $\mathrm{CO}_{2}$ during the process. For further calculation the temperature distribution (figure 4.) can help us to optimize the boiler geometry and to make a more effective heat transfer surface.

\section{Conclusion}

With the presented method, we were able to simulate a multi species, complete combustion in ANSYS Fluent 19.1. The simulation showed good convergence. Our further measurement goal to create a more precise geometry model of the boilers. With measured gas composition and emissions, the emissions error can be calculated and by developing a finer model this error can be reduced. With good converging models it will be easier to design effective gas burners and with that the $\mathrm{CO}_{2}$ emissions can be reduced.

\section{References}

[1] R. Filkoski and I. Petrovski (2002) Computational fluid dynamics in function of boilers' revitalization Faculty of Mechanical Engineering, Dubrovnik.

[2] „VASFA Szolnoki Kazángyártó Kft.,” [Online]. Available: http://www.vasfa.hu/angol/musz_adat/ma_kaz_viz.html. [accesed: 20. 09. 2018.].

[3] „VASFA Szolnoki Kazángyártó Kft.” [Online]. Available: http://www.vasfa.hu/magyar/ref_list.html. [accesed: 01. 09. 2018.].

[4] S. R. Turns (2013) An Introduction into Combustion concepts and applications, India: Mc Graw Hill Education.

[5] P. Wandel - T. Yusaf (2013) etail Guide for Cfd On The Simulation Of Biogas Combustion In BluffBody Mild Burner Andrew, Computational Engineering and Science Research Centre Australia.

[6] M. L. Indrusiak - C. V. da Silva - A. B. Beskow - J. W. M. Kaehler (2007) CFD analysis of the combustion. gas flow. and heat exchange processes in a boiler of a thermal power plant. in Research Group of Energy Production Systems, Catholic University of Rio Grande do Sul.

[7] A. Devadiga - T. N. Rao (2013) Optimizing Bunsen burner Performance Using CFD Analysis. in Oxford College of Engineering, Bangalore. 